\title{
Очерки
}

УДК 338.266

Пространственная Экономика

2012. № 3. C. $135-158$

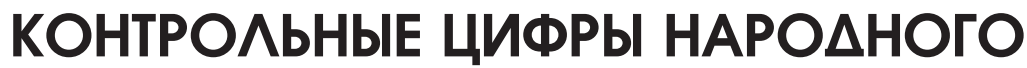

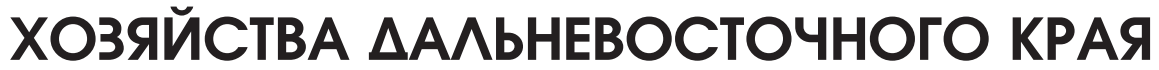 HA 1926-1927 гr.'}

Представлены контрольные цифры народного хозяйства Дальнего Востока, проектируемые Дальневосточной краевой плановой комиссией на 1926-1927 гг. Проведен анализ всех элементов по основным общественным секторам: государственному, кооперативному и частному, чтобы установить их динамику и взаимоотношения в народном хозяйстве края. Увязка отдельных частей системы между собой осуществлялась частью методом баланса, частью способом поверочных коэффициентов.

Народное хозяйство, контрольные цифры, директивы, Дальневосточная плановая комиссия, Дальний Восток.

\section{VI. ЦЕНЫ}

Общий уровень оптовых цен на 1926-1927 гг. проектируется совершенно стабильным. Сельскохозяйственный субъиндекс, давший в 1925-1926 гг. 8\%-й прирост, проектируется на 1926-1927 гг. с приростом в 1\%, а промышленный, обнаруживший стабильность в 1925-1926 гг., проектируется с 1\%-м понижением. В результате 1926-1927 гг. дают сближение лезвия ножниц. Сдвиги цен, намечаемые на 1926-1927 гг. по отдельным отраслям хозяйства, характеризуются, однако, значительным разнообразием направления и темпа. <..>

I. Зернофуражная группа. 8\%-е снижение среднегодового уровня зернофуражных цен обосновывается следующим анализом движения кривой зернофуражной группы за два предшествующих года (1924-1925 гг. и 19251926 гг.) и экономической обстановки 1926-1927 гг.

Низкий уровень зернофуражных цен в I полугодии 1924-1925 гг. сменяется резко повышательным движением во II полугодии этого года и относительной стабилизацией высокого уровня цен на протяжении 19251926 гг. <..>

Повышательный сдвиг цен зернофуража должно отнести не к влиянию факторов конъюнктурного порядка, а к глубокому органическому процессу выравнивания рыночных эквивалентов сельхозпродуктов (овес, пшеница), соответственно новым (сложившимся после периода депрессии с. х. в 19201923 гг.) нормам и пропорциям производственных затрат в сельском хозяйстве.

\footnotetext{
${ }^{1}$ Окончание. Начало см. в журнале «Пространственная экономика». 2012. № 1. С. 109-134.

Контрольные цифры народного хозяйства Дальневосточного края на 1926-1927 гг. / Дальневосточная краевая плановая комиссия. Хабаровск: Книжное дело, 1926. 97 с.
} 
Исходя из этих предпосылок, необходимо предположить, что основной направляющей тенденцией хлебных цен в 1926-1927 гг. будет сохранение сложившегося уровня, то есть стабильность цен. Однако влияние понижающихся сибирских цен усилит проявление по краю сезонных колебаний цен на местный хлеб в I полугодии (снижение) и усилит инерцию сложившегося (несколько пониженного) уровня цен во II полугодии.

В связи с этим амплитуда сезонного колебания (снижения в I полугодии), выражающаяся в среднем для двухлетия в 6-7\%, в 1926-1927 гг. увеличится предположительно до 15\%, имея нижайшей точкой декабрь - январь месяцы. Наоборот, амплитуда колебания (повышения) в периоде февраль - май, выражающаяся в среднем для двухлетия в 15\%, под усилившимся влиянием инерции снизится предположительно до 7\%. Период май - июль даст полную стабильность, а август - сентябрь - незначительное сезонное снижение уровня цен.

II. Мучная и крупяная группа. Кривая индекса мучной и крупяной группы за 1924-1925 гг. - 1925-1926 гг. в общем повторяет движение кривой зернофуража, правда, при значительно большей плавности уровня как в периоды непрерывного повышения цен (II полугодие 1924-1925 гг.), так и в периоды сезонных снижений.

Исходя из этого свойства кривой мучной и крупяной группы, несомненно, обусловленного регулирующей деятельностью узкого контингента оптовых распределителей в условиях почти полной фактической монополии их на оптовом рынке, необходимо предположить, что цены 1926-1927 гг., отражая движение цен зернофуража, сохранят также значительно большую плановость уровня. Среднегодовой уровень цен снизится на 5\% против $8 \%$ снижения по зернофуражной группе.

III. Сырьевая группа. Кривая сырья (семя льняное, бобы, кожа скотская и шерсть), обнаружив в 1924-1925 гг. резко повышательный сдвиг, в 19251926 гг. в общем стабилизируется на достигнутом уровне, несколько снижаясь в I полугодии и повышаясь во II полугодии.

Исходя из предположения, что достигнутый уровень в основном связан также с восстановительным движением цен на животное сырье, и что условия наступающего года будут, по всем данным, характеризоваться усилением накопления капиталов в скоте и сдержанностью его предложения, что устойчивая конъюнктура на рынках сбыта бобов и льняного семени (при недороде последних) будет способствовать повышению цен на это сырье, считается возможным повышение на $6 \%$ среднегодового уровня цен на сырье по сравнению с предыдущим годом.

IV. Мясная группа. Кривая мясной группы 1925-1926 гг. обнаружила весьма плавное движение, в отличие от 1924-1925 гг, давших после резкого 
сезонного снижения в осенние месяцы непрерывное повышение в течение полугодия с последующим снижением в IV квартале.

Исходя из предположений, что имеющий место процесс восстановления рыночных эквивалентов продуктов животноводства не закончился, что общеэкономические условия в наступающем году будут вызывать усиление накопления капиталов в скоте, что специфические условия конъюнктуры мясного рынка во II полугодии 1925-1926 гг, приведшие к резкому повышению розничных и мелкооптовых цен, не нашли еще отражение в оптовых ценах госзаготовителей, так как сезон заготовок был окончен, - считается возможным повышение среднегодового уровня мясных оптовых цен в 1926-1927 гг. на $18 \%$ против предыдущего года.

V. Пушная группа. В 1926-1927 гг. остается вполне стабильной.

VI. Рыбная группа. Кривая рыбной группы после резко повышательного сдвига (в связи с недоловом) летом 1924-1925 гг. и последующего снижения в осенние месяцы на протяжении I квартала почти в полной мере снова восстанавливает высокий летний уровень и стабилизируется на нем в продолжение 1925-1926 гг.

Исходя из предположения, что хороший улов 1925-1926 гг. и увеличение значения государственных и кооперативных заготовителей будет способствовать снижению ненормально возросших цен на рыбопродукты, считается возможным для 1926-1927 гг. принять среднегодовой уровень цен 1924-1925 гг.

VII. Бакалейная, металлическая, текстильная и кожевенная группы. Исходя из директивного положения Госплана Союза о стабильности отпускных промышленных цен в 1926-1927 гг, обуславливаемого, вопреки организационно-технической рационализации промышленного производства, возможным ростом цен на сельскохозяйственное сырье при стабильности заработной платы - в качестве основной предпосылки при проектировании оптовых промышленных цен на 1925-1926 гг. по краю принимается стабильность их общего уровня.

В связи, однако, с наличием в составе общей промышленной товарной массы края продукции местной промышленности, испытывающей различные реорганизационные и реконструктивные процессы специфического характера, необходимо учесть при проектировании движения уровня промышленных цен эти специфические факторы. <...>

VIII. Tопливная группа. Исходя из расчета все возрастающей диспропорции между ростом внутреннего рынка минерального топлива и его добычи, неустранимой без перехода на удорожающую себестоимость разработку глубоких пластов, в целях усиления капиталонакопления в краевой каменноугольной промышленности необходимо повышение среднегодового уровня цен на 10\%. В связи с растущими ценами на рабочие руки и недостатком 
рабочей силы для расширения хозяйственных дровозаготовок общественных и государственных организаций, считается возможным также 10\%-е повышение среднегодового уровня цен на дровяное топливо.

В соответствии с этим предполагается повышение индекса топливной группы на $10 \%$.

IX. Лесная группа. Исходя из удорожания рабочей силы, занятой в лесозаготовках, предполагается повышение себестоимости лесоматериалов на $10 \%$, но, учитывая снижение нормы накладных торговых расходов, принимается 7\%-е повышение среднегодового уровня индекса лесной группы.

Х. Химическая группа. В связи с сооружением гидрогенизационного завода предполагается снижение цен на техническое сало на 10\%, что, учитывая вес его в химической группе, обусловливает общее снижение среднегодового индекса группы на $3 \%$.

В результате происшедших ценностных смещений внутри сельскохозяйственных товаров в пользу животноводства (мясо, сырье), а внутри промышленных товаров в пользу наиболее отставших по ценностному уровню отраслей (лесопромышленность, каменноугольная промышленность), индексы коих абсолютно ниже довоенного уровня, обеспечивается необходимое плановое перераспределение средств, способствующее усилению капиталонакопления в этих отраслях хозяйства.

\section{TOВАРООБОРОТ}

Трудности учета торгово-посреднического товарооборота по всем составляющим элементам в значительной мере препятствуют изучению экономических проблем торговли народнохозяйственного значения. Во всяком случае, вне балансового изучения народного хозяйства остается чрезвычайно мало возможностей для выявления таких моментов, как отношение части товарной массы, охватываемой торговым посредничеством ко всей товарной массе, скорость товарного обращения, совокупные и дифференцированные (по звеньям) общественные издержки на торговлю и их удельный вес в народном доходе и т. д.

Но в условиях нашей экономической действительности показатели товарооборота (и таково их назначение в системе контрольных цифр) остаются важнейшими показателями динамики обобществления важнейшего участка экономического фронта - рынка, отражающего связь и зависимость всех социально-экономических групп. <...>

Весь торгово-посреднический товарооборот в 1926-1927 гг. ровно вдвое превысил товарооборот исходных 1923-1924 гг., обнаружив все же меньший по темпу восстановительный подъем, чем по Союзу в целом (250\%, 
с 9,75 млрд руб. до 24,4 млрд руб.), вследствие и меньшего функционального распада хозяйства края к исходному периоду. Удельный весь всего общественного сектора в товарообороте края непрерывно растет до 1925-1926 гг. включительно, а удельный вес частного сектора непрерывно падает. <...>

Условия товарооборота 1926-1927 гг. в общем и целом будут весьма близкими условиям 1925-1926 гг. На узловом участке рынка - товарообороте деревни 1926-1927 гг. - будет проходить под несомненным воздействием диспропорций спроса и предложения. Приводимый ниже ориентировочный товарный баланс города и деревни устанавливает нарастание денежного сальдо деревни в связи с недостаточным предложением промтоваров. Но вместе с тем и на этом участке товарооборота 1926-1927 гг. дают значительные результаты, поскольку нарастание денежного сальдо деревни в 1926-1927 гг. значительно ослабевает по темпу по сравнению с 1925-1926 гг.

Проектируемый объем товарной массы, главным образом, в части предметов широкого потребления, ввозимых из центральных районов, позволяет не пропустить обострения товарного голода деревни и расширения диспропорции спроса и предложения. <...>

\section{VIII}

А. Кредит. Истекшее трехлетие характеризуется чрезвычайно интенсивным ростом кредита в ДВК. Но темп этого роста, будучи сам по себе чрезвычайно быстрым, отличался большой неравномерностью, в силу качественно разнородных процессов, обусловливающих развитие кредитной системы ДВК внутри рассматриваемого периода.

За три года движение основных показателей по кредиту дает такую картину: капиталы с 6,9 млн увеличились до 38 млн, текущие счета с 5,5 млн увеличились до 17 млн, учетно-ссудные операции с 9 млн увеличились до 47 млн.

Иными словами: капиталы увеличились в 5,5 раза, учет и ссуды в 5,2 раза и текущие счета - в 3,1 раза.

Но темп процесса из года в год весьма различен. <...>

В течение первого года развитие кредитной системы характеризуется чрезвычайно бурным ростом всех показателей. Второй год дает огромное снижение темпа, и в третьем году снова намечается ускорение.

Эти скачки в движении кривой развития кредита в ДВК объясняются качественной разнородностью лежащих в основе его факторов. В то время как в 1923-1924 гг. имело место организационное развертывание кредитной системы края (расширение сети), в 1924-1925 гг. начинается органический рост на основе уже достигнутого организационного уровня. В первом случае процесс носит экстенсивный характер, во втором - интенсивный. Лучшим 
подтверждением и наиболее яркой иллюстрацией этого положения может служить динамика привлеченных пассивов. В 1923-1924 гг. они дают рост в 241\%, в 1924-1925 гг. только 29\% и в 1925-1926 гг. остаются стабильными. Совершенно очевидно, что быстрый рост 1923-1924 гг. объясняется не увеличением остатков свободных средств народного хозяйства края, а просто улучшением и количественным увеличением банковского аппарата, увеличением количества тех всасывающих машин, посредством которых банки перекачивают в свои кассы избыточные и временно свободные средства данного района. 1924-1925 гг. показывают окончание этого процесса собирания и 1925-1926 гг. свидетельствуют уже о полном исчерпании местных источников. Роста текущих счетов в этом году нет, несмотря на усилившийся темп кредитования (46\% против $32 \%)$.

Этот факт с несомненностью указывает на чрезвычайно напряженное положение краевой кредитной системы. Таким образом, кредитование краевого хозяйства происходит, главным образом, за счет средств внекраевого происхождения <...>.

Доля участия местных пассивов, таким образом, неуклонно падает, причем особенно резко падение это происходит как раз в 1925-1926 гг. При возрастающей же потребности в кредите и при стабильности местных пассивов безболезненное развитие кредита может происходить только при условии бесперебойного достаточного снабжения местных филиалов центральных банков оборотными средствами, что ставит местное хозяйство в полную зависимость от кредитной конъюнктуры центральных частей СССР и должно быть соответствующим образом учтено. В противном случае при автоматическом снижении кредитов, без учета краевых хозяйственных и сезонных специфических условий, как это имело место в некоторые моменты 19251926 гг, краевому хозяйству может быть нанесен большой урон.

Стабильность текущих счетов в 1925-1926 гг. обусловливается исчерпанием местных источников и большой потребностью краевого хозяйства в деньгах, вследствие чего выделение из оборота избыточных средств и не могло иметь места.

Что касается показателей по кредитованию отдельных секторов краевого хозяйства, то здесь наиболее быстрый рост дают показатели по госсектору, кредитование которого за три года увеличилось в 8,5 раза; коопсектор дает рост в 4 раза и частный увеличивается всего на одну треть. В пределах каждого года темпы опять-таки резко различны.

Соответственно этому изменяется и удельный вес отдельных хозяйственных групп в общей сумме учетно-ссудных операций банков ДВК. <..>

В отношении текущих счетов наблюдаются несколько иные тенденции. За три года наибольший рост дают пассивы кооперации (374\%), затем идут 
частники (340\%) и медленнее всех растут пассивы госсектора (303\%). В частности, 1925-1926 гг. характеризуются некоторым падением пассивов госсектора (-2\%), резким замедлением по кооперации (7\%) и меньшим по частникам (22\%). Более быстрый, сравнительно с другими, рост частного сектора объясняется развитием в 1925-1926 гг. деятельности Обществ Взаимного Кредита, начало организации которых относится к концу 1924-1925 гг. <..>

Что касается капиталов, то показатели по ним отличаются наиболее резкими изменениями темпа. За три года госсектор увеличил свои капиталы в 37,2 раза, кооперация - в 6 раз и частники выросли всего на $25 \%$.

В 1925-1926 гг. госсектор увеличивается больше, чем на две трети, кооперативный на $16 \%$ падает и частный увеличивается в два с половиной раза $(155 \%)$. Рост частного сектора объясняется исключительно организацией и развитием сети ОВК. <..>

При построении контрольных показателей на 1926-1927 гг. следует исходить, прежде всего, из учета тех соотношений, которые имели место в предшествующем году между движением товарной массы, с одной стороны, и увеличением банковских вложений в краевое хозяйство - с другой. Соотношения эти для всего рассматриваемого периода характеризуются чрезвычайной устойчивостью, колеблясь от 3,8 до 4,4 (отношение прироста товарной массы к приросту задолженности). Принимая во внимание общую благоприятную конъюнктуру, которая намечается в 1926-1927 гг. и, в частности, учитывая значительный прирост потребительских кредитов по линии кредитования переселенцев, можно для 1926-1927 гг. принять максимальное из указанных соотношений $(3,8)$, что при увеличении товарной массы на 50 млн руб. дает увеличение задолженности на 13 млн руб.

Отсюда уровень учетно-ссудных операций на 1.10 .1927 г. выразится в сумме 60 млн черв. руб.

Наиболее быстрый рост задолженности пойдет по линии частного сектора, так как в 1926-1927 гг, в связи с усилением колонизации, следует ожидать значительного увеличения переселенческих кредитов.

По утвержденному уже плану колонизации в 1926-1927 гг. предполагается водворение в ДВК 10000 семей, что при ссуде на семью в 400 руб. дает общую величину переселенческого кредита в 4 млн руб. Если даже из осторожности считать, что план колонизации будет выполнен лишь на 75\%, то и в этом случае рост ссудных операций по этой линии выразится в 3 млн руб. Исходя из этих соображений, общую сумму задолженности частного сектора на 1.10.1927 г. можно определить в размере 6 млн руб., относя, таким образом, почти весь прирост за счет переселенческих кредитов и увеличивая коммерческие кредиты всего на 180 тыс. руб., или на 7\%, при общем увеличении задолженности частного сектора на $113 \%$. <...> 
Необходимый размер оборотных средств определяется из соотношения соответствующих показателей за предшествующие годы. Процент учетноссудных операций ко всей сумме оборотных средств банков ДВК за два последние года колеблется от 84,1 до 85,4 . <..>

Однако распространять эти соотношения на будущее время нет достаточных оснований, поскольку: 1) общая линия банковской политики направлена сейчас в сторону всемерного сокращения товаро-комиссионных операций и полного прекращения товарных операций за собственный счет; 2) валютные операции, несомненно, не возрастут и 3) касса должна будет понизиться. Поэтому представляется возможным на 1926-1927 гг. размер прочих реальных активов банков ДВК оставить на уровне 1925-1926 гг, то есть 8 млн руб. Таким образом, вся сумма оборотных средств должна составить 68 млн руб.

При распределении этой суммы на капиталы и текущие счета необходимо учитывать, что разница темпов роста этих элементов неизбежно будет иметь место и в 1926-1927 гг. Перспективы увеличения местных пассивов вообще довольно проблематичны, и вряд ли это увеличение будет идти за счет реального накопления свободных резервов. Скорее всего, большая доля прироста текущих счетов придется на перечисление открытых кредитов на текущие счета клиентов.

Дело в том, что хотя общая конъюнктура краевого хозяйства складывается достаточно благоприятно, тем не менее такие отрасли его как госпромышленность и госторговля, в 1926-1927 гг. не выйдут из состояния финансового напряжения, так что ожидать сколько-нибудь значительного роста их текущих счетов нет оснований. Увеличение же денежных излишков населения вследствие хорошего урожая и благоприятных результатов рыбного лова на банковских пассивах, конечно, не отразится, поскольку денежные накопления населения резервируются, главным образом, в сберкассах или же помещаются в государственные займы ${ }^{1}$.

Исходя из этих соображений, контрольный показатель по текущим счетам определен в сумме 18 млн руб. при уровне на 1.10.1926 г. в 17 млн руб., что дает $6 \%$ прироста. В абсолютных величинах рост этот почти весь проходит по линии госсектора (920 тыс. увеличения), соответственно размерам его кредитования. Пассивы кооперации оставлены стабильными и текущие счета частников предположены к увеличению на 180 тыс. руб., главным образом за счет дальнейшего развития и интенсификации деятельности ОВК. <...>

\footnotetext{
1 Вклады в сберкассы здесь совершенно не учитываются, так как суммы эти в хозяйственном обороте ДВК не участвуют. Насколько значительно накопление мелких сбережений, можно видеть из того, что за 1925-1926 гг. остаток вкладов увеличился с 405 тыс. руб. до 1400 тыс. руб., к концу 1926-1927 гг. предположено довести его до 3000 тыс. руб.
} 
При общей сумме оборотных средств в 68 млн руб. и уровне текущих счетов в 18 млн руб. размер капиталов определяется в 50 млн руб. Сумма их на 1.10.1926 г. составляла 38 млн руб. Таким образом, в течение 1926-1927 гг. капиталы должны увеличиться на 12 млн руб., или на $32 \%$.

В абсолютных цифрах рост этот должен пойти, главным образом, по линии госсектора (11 725 тыс. руб.); некоторое увеличение проектируется по кооперации (200 тыс. руб.) и частникам (75 тыс. руб.). Рост капиталов последних предположен исключительно по линии ОВК.

Из 12 млн прироста капиталов основная масса приходится, конечно, за счет притока их извне, так как внутреннее капиталонакопление краевой кредитной системы не превысит 1,5 млн руб. Таким образом, 10,5 млн должны быть получены извне. Из этой суммы около 4,5 млн падает на целевые капиталы Дальсельбанка (колонизационные кредиты) и 6 млн должен будет дать Госбанк. <...>

Ныне бюджетная обстановка складывается совершенно иначе. Край фактически живет в условиях почти замкнутого бюджета, вследствие чего и исчезли причины, вызывавшие разбухание местных пассивов, и последние снизились до естественного уровня возможного резервирования местных средств, которые, по общему состоянию краевого хозяйства, не могут быть особенно велики. По существу же картина не изменилась. И в 1913 г. кредитование хозяйства ДВК происходило за счет привлеченных извне средств, только тогда средства эти попадали в банки через передаточную инстанцию в лице государственного казначейства; теперь же они притекают просто в порядке пополнения оборотных капиталов местных филиалов центральных банков.

Б. Денежная масса. Учет изменений объема денежной массы какого-либо района может в существующих условиях идти исключительно по линии местных учреждений центрального эмиссионного банка, так как только эти последние фактически осуществляют регулирование размеров денежного обращения.

Выпуск новых денег в обращение происходит сейчас исключительно в порядке кредитных операций, эмиссия используется как один из источников пополнения оборотных средств банков ${ }^{1}$ Поэтому определение вероятного размера денежной массы данного района на предстоящий период времени приходится строить на учете тех ресурсов, которые предположены ко вложению в народное хозяйство местной системой центрального эмиссионного банка.

1 Конечно, это капиталообразование за счет эмиссии может происходить лишь в меру реального накопления капиталов и должно находиться в полном соответствии с интересами денежного обращения, в частности, с задачей сохранения устойчивости денежной единицы. 
Контрольными цифрами по кредиту запроектировано помещение в народное хозяйство ДВК новых банковских средств 12 млн руб., из которых на долю средств внекраевого происхождения приходится 10,5 млн руб. Увеличение же оборотных средств ДВ системы Госбанка предположено в 6 млн руб.

Эту сумму и представляется возможным принять, как увеличение денежной массы ДВК в течение 1926-1927 гг.

Таким образом, на 1.10.1927 г. денежная масса края должна составить 37 млн руб., что дает увеличение за год на 19\% (при росте за 1925-1926 гг. на 39\%). Среднегодовая величина денежной массы составит, следовательно, 34 млн руб. при соответственном показателе 1925-1926 гг. в 27 млн руб.

Здесь уместно будет остановиться на одном из моментов, характеризующих, так сказать, баланс взаимных расчетов между ДВК и СССР.

Как видно, краевое хозяйство обслуживается преимущественно капиталами, полученными из центра. Цифровая характеристика этого положения дана в разделе о кредите.

Внутреннее капиталонакопление пока еще не поспевает за ростом потребностей народного хозяйства ДВК, и развитие последнего в течение еще некоторого промежутка времени должно будет происходить за счет внекраевых ресурсов.

Увеличение денежной массы данного района можно рассматривать по существу как местную эмиссию. Но как всякая эмиссия, она может идти лишь за счет реального накопления внутри данного хозяйственного комплекса. Поэтому, говоря о необходимом увеличении денежной массы в ДВК, нужно сопоставить эту величину с размерами денежного накопления населения.

В течение 1926-1927 гг. в ДВК предусматривается реализация госзаймов на 1250 тыс. руб. Вклады в сберкассах предположено довести до 3 млн руб. Таким образом, из 6 млн увеличение денежной массы 4250 тыс. руб. представляют собою фактически лишь возврат средств, изъятых из хозяйственного оборота края в порядке госкредитных операций.

Что касается непокрытого остатка в 1775 тыс. руб., то в отношении его можно сказать следующее. В 1926-1927 гг. ДВК должен дать золота на сумму около 10 млн руб. Для указанного непокрытого остатка увеличение денежной массы («краевой эмиссии») необходимо 440 тыс. руб. золотого покрытия, считая по нормам Союзного эмиссионного законодательства. Эти 440 тыс. руб. золота составляют всего лишь 4,4\% того увеличения золотого фонда Союза, которое должна будет дать золотопромышленность ДВК в 1926-1927 гг.

Таким образом, предполагаемое увеличение денежной массы края целиком и полностью покрывается как размерами внутреннего накопления населения, так и теми взносами, которые ДВК делает в общесоюзный золотой фонд. <...> 


\section{IX. БЮДЖЕТ}

$<$...> В 1923-1924 гг. и 1924-1925 гг. дефицитность госбюджета края целиком вызывалась дефицитностью казенного хозяйства и расходами по финансированию народного хозяйства, причем эти расходы частично покрывались поступлениями по госбюджету края. В 1925-1926 гг. и 1926-1927 гг. дефицитность госбюджета вызывается, главным образом, этими же причинами и в 1925-1926 гг. лишь 6647 тыс. руб. (22,2\% общего дефицита) вызывается расходами другого назначения, а в 1926-1927 гг. они вызывают дефицитность лишь на 5136 тыс. руб. (11\% общего дефицита). <...>

Неуклонный и значительный рост дают капитальные затраты и расходы по усилению местных средств. Наравне с ростом всего бюджета увеличиваются расходы по зарплате. Административно-хозяйственные расходы несколько отстают от общего роста и значительно отстают операционные расходы. <...>

Отсюда можно заключить, что:

1. Местные неналоговые доходы обнаруживают значительный рост, парализованный в 1926-1927 гг. неизъятием прибылей коммунальных предприятий, переводимых на хозрасчет.

2. Местные налоговые доходы растут в соответствии с ростом всего бюджета.

3. Значение отчислений и пособий из госбюджета резко меняется в 19261927 гг. в связи с переходом на новое положение о местных финансах. Значение этой статьи дохода, понижавшееся из года в год, с 1926-1927 гг. выдвигается на первое место.

4. Остальные доходы, значение которых в 1925-1926 гг. увеличилось благодаря тому, что тогда эти доходы (остатки бюдж. средств) исчислялись дважды (на II полугодие составляется отдельный бюджет), в 1926-1927 гг. фигурируют в нормальных цифрах.

5. Значение фонда регулирования (оборотные суммы), повысившееся в 1925-1926 гг. вследствие перестройки бюджета, по урегулировании техники строения бюджета резко понизилось. $<\ldots>$

Отсюда видно, что:

1. Расходы по управлению увеличиваются из года в год в соответствии с общим ростом бюджета.

2. Расходы по обороне, отстававшие от общего роста бюджета, значительно увеличиваются в 1926-1927 гг. в связи с переходом на новую форму финансирования (возмещение из госбюджета).

3. Социально-культурные расходы значительно увеличиваются из года в год, далеко опережая рост всего бюджета. Удельный вес этих расходов в бюджете повышается в 1926-1927 гг. до 40\%. 
4. Административно-хозяйственные расходы развертывались достаточно интенсивно. Резкое понижение их в 1926-1927 гг. вызывается переводом на хозрасчет коммунальных предприятий, которые благодаря этому совершенно выпали из расходной части бюджета.

5. Расходы по финансированию народного хозяйства росли чрезвычайно интенсивно. Снижение удельного веса их в 1926-1927 гг. вызвано также, главным образом, переводом на хозрасчет коммунальных предприятий.

6. Остальные расходы, состоящие из погашения задолженности и отчислений в специальные капиталы, не развиваются за понижением сумм задолженности. <...>

Резюмируя все вышесказанное, можно видеть, что госбюджет 19261927 гг. характеризуется:

1. Общим увеличением доходов на 20,5\%, отмечающимся по всем группам доходов, причем увеличение происходит за счет следующих основных источников: прямые налоги - 14,1\%, акциз со спирта - 25\%, гербовый сбор $21 \%$, лесной доход - 38\%, доход рыбопромысловых угодий - 23\%, транспорта и связи - 20\% и чрезвычайных доходов - 57\%. Незначительность роста поступлений по всем акцизам, взятым вместе, объясняется невключением в смету поступлений в сумме 1900 тыс. руб., имеющих поступить вне пределов края. С учетом этой суммы косвенные налоги дадут увеличение на 19,6\% вместо показанного $1 \%$, а общее увеличение доходов составит $23 \%$.

2. Значительным увеличением расходов, составляющим $32 \%$ и происходящим, главным образом, за счет увеличения ассигнований на социально-культурные нужды, казенное хозяйство и финансирование народного хозяйства.

3. Вытекающим из различия в темпе роста доходов и расходов увеличением дефицитности госбюджета края, причем назначение средств, притекающих извне на покрытие дефицита, определяется в большей степени нуждами казенного хозяйства и финансирования народного хозяйства.

4. Наибольшим увеличением расходов по финансированию народного хозяйства и по вспомоществованию местному бюджету.

Местный бюджет края на 1926-1927 гг. характеризуется:

1. Понижением общей суммы доходов по бюджету на 4,3\%, вызываемым переводом на хозрасчет коммунальных предприятий и сокращением суммы свободных средств, при наличии значительного увеличения отчислений от госдоходов и госналогов.

2. Соответствующим понижением общей суммы расходов, вызываемым исключением расходов по коммунальным предприятиям, что уменьшает расходы по финансированию народного хозяйства и административно-хозяйственные расходы; наряду с этим отмечается значительный рост расходов социально-культурных, по управлению и обороне. 


\section{Х. ТРУД}

Настоящий раздел в контрольных цифрах ДВК на 1925-1926 гг. отсутствовал и в настоящей работе появляется впервые. Однако относительная сложность учета и вместе с тем слабость статистики труда обязывают к выводам подходить очень осторожно.

Обращаясь прежде всего к роли наемного труда во всем количестве занятых лиц, мы видим, что его доля постепенно растет <... $>$.

Таким образом, можно констатировать некоторую пролетаризацию населения ДВК (особенно если принять во внимание рост госсектора). При этом интересно отметить, что доля наемного персонала в ДВК $(17,7 \%)$ на 1926-1927 гг. выше, чем по СССР (14\%).

Основные кадры наемного персонала приходятся на промышленность, транспорт и госучреждения. <...>

Количество наемного труда на 1926-1927 гг. проектируется из учета развертывания соответствующих отраслей народного хозяйства и из предполагаемого роста производительности труда. Перспективы здесь складываются такие:

a) в каменноугольной промышленности, судя по сложившейся динамике, можно ожидать не только роста, а скорее понижения, в силу вероятности дальнейшего увеличения доли желтого труда с пониженной производительностью, так как русские рабочие не удовлетворяются существующим уровнем зарплаты. Однако в контрольных цифрах принят принцип непонижения уровня производительности труда, в связи с чем проектируется некоторое повышение зарплаты;

б) предполагается повышение производительности труда, главным образом за счет обслуживающего персонала на металлообрабатывающих предприятиях ввиду сильного повышения загрузки их (Дальсельмаш на 40\%, Дальзавод на 25\%);

в) по лесопильно-фанерной предполагается повышение производительности труда до 17\%, имея в виду повышение загрузки некоторых предприятий до 100\% против 1925-1926 гг.;

г) по пищевкусовой (винокуренной, маслобойной, пиво-медоваренной, прочей пищевкусовой), в связи с резким повышением нагрузки (от 30 до $40 \%)$, предполагается повышение производительности труда на $10 \%$. Исключение из этой группы составляет мукомольная, где производительность труда, в результате технической обветшалости предприятий, вряд ли можно будет поднять больше 5\%;

д) в прочих отраслях обрабатывающей цензовой и мелкой промышленности производительность труда, вероятно, останется без изменений, так как рост нагрузки в них относительно невелик и никаких сколько-нибудь серьезных технических усовершенствований не предвидится; 
е) в таком же положении находится и строительное дело в ДВК, обслуживаемое исключительно китайским малоквалифицированным трудом. Средств повышения его квалификации сейчас не имеется никаких. Попытки привлечь строительных рабочих с запада успеха не имели. Кроме того, все работы ведутся самыми примитивными способами вследствие недостатка капиталов у строительных организаций. На 1926-1927 гг. положение не изменится и потому рассчитывать на повышение производительности труда не приходится;

ж) для транспорта и связи в результате повышения их нагрузки и крупного повышения зарплаты, что позволяет там подбирать наиболее квалифицированные кадры, предполагается повышение производительности труда в пределах 7-8\%;

3) в торговле, при повышении товарооборота на 13\%, рост персонала предполагается всего на $3 \%$, с отнесением остального на счет роста производительности труда;

и) в группе наркоматских учреждений учесть производительность труда представляется невозможным. Поэтому там принято на 1926-1927 гг. контингентное количество работников (по бюджету), равное 1925-1926 гг. Принимая, однако, во внимание, что нагрузка соваппарата должна расти приблизительно пропорционально росту общего объема народнохозяйственной жизни и что этот последний должен колебаться для 1926-1927 гг. около 13-15\%, следует предполагать, что нагрузка этой группы рабочих увеличится около $15 \%$;

к) в незначительных по объему группах прислуги и сельскохозяйственных рабочих учесть производительность труда невозможно. Учитывая, что группа прислуги из года в год дает примерно 10\% роста, для 1926-1927 гг. ее количество увеличено (с округлением) на этот же процент.

Группа же сельскохозяйственных рабочих за пореволюционные годы имеет тенденцию к сильному неуклонному снижению. Далькрайплан полагал, однако, что 1926-1927 гг. дадут перелом в этой тенденции в силу растущего расслоения в деревне и прилива нуждающихся в заработке переселенцев.

В результате всех этих расчетов 1926-1927 гг. дают повышение количества наемной силы на 8\%. Процент этот ниже тех, что наблюдались за ближайшие прошлые годы (1925-1926 гг. - 16\%, 1924-1925 гг. - 9,2\%). Это объясняется, с одной стороны, меньшим ростом объема хозяйства в наступающем году, чем в прошлых, а с другой и ростом производительности труда.

По отношению к приросту продукции отраслей хозяйства, использующих в больших размерах наемную силу (рыболовство, лесозаготовки, промышленность, транспорт и строительство), где объем продукции 19261927 гг. больше против 1925-1926 гг. на 16\%, количество наемного труда также отстает в результате повышения его производительности. 
К вопросу проектирования уровня зарплаты Далькрайплан подходил со следующими принципиальными положениями:

a) намеченная стабилизация оптовых цен, с понижением их по таким важным элементам рабочего бюджета, как мучные и крупяные продукты $(-5 \%)$, бакалейно-продовольственные $(-2 \%)$;

б) продолжение государственных мероприятий по снижению розничных цен, что должно, вместе с первым предположением, еще более повлиять на повышение покупательной способности зарплатного рубля;

в) принципиальную недопустимость снижения зарплаты ни в одной из отраслей труда с необходимостью вместе с тем подтянуть зарплату в отставших отраслях.

Проектирование зарплаты велось в червонных рублях с переводом на московские рубли по бюджетному индексу 1925-1926 гг. Это несколько преуменьшает повышение реальной зарплаты, поскольку предполагается некоторое снижение розничных цен. <...>

В общем доля зарплаты в объеме соответствующей валовой продукции повышается, но главная доля этого повышения приходится на группу транспортников. В частности, на 1926-1927 гг. доля заработной платы во всей продукции (без транспорта) сохранена на уровне 1925-1926 гг. <..>>

В результате всего вышеизложенного, а также имея в виду повышение цен сырья и топлива и сомнительность сколько-нибудь серьезной рационализации, рассчитывать на особенно большой рост капиталонакопления (централизованного) трудно. <...>

Роль государственного сектора растет за счет частника в отношении количественного охвата пролетариата при почти полной устойчивости доли кооперативного сектора.

Вместе с тем выявляется, что оплата пролетариата, занятого в государственном секторе, растет сильнее, чем в прочих. Это обеспечивает ему и наилучшие кадры пролетариата и соответствует его значению и роли в совсистеме.

1926-1927 гг. вносят в этом отношении дальнейшее улучшение. Вместе с тем необходимо обратить внимание на ухудшение положения в этом отношении в кооперативном секторе.

В заключение остановимся на соотношении движения уровня заработной платы по СССР в целом и по ДВК за пореволюционные годы, принимая 1923-1924 гг. $=100 .<\ldots>$

По темпу нарастания уровня зарплаты ДВК значительно отстает от СССР. Принимая во внимание окраинное положение ДВК и затруднения с подбором рабочей силы, особенно квалифицированной (забойщики, строители, химики и пр.), это явление следует признать ненормальным. 19261927 гг. пытаются несколько выправить положение, и потому предполагается несколько больший $(13,8 \%)$ рост средней зарплаты, чем по СССР $(6,2 \%)$. 
№ 22012

\section{ХІ. ОСНОВНЫЕ ФОНДЫ И КАПИТАЛЬНЫЕ ВЛОЖЕНИЯ}

Изучение динамики накопления основных фондов в дальневосточном хозяйстве ставится впервые, как один из элементов программы контрольных цифр народнохозяйственного края.

В области изучения основных капиталов нет готовых объектов учета, поэтому все данные по отдельным отраслям хозяйства являются итогом обработки, зачастую сырого, материала, полученного от организаций и ведомств.

Этим в большой мере объясняется некоторая неполнота материала. В основном капитале по сельскому хозяйству отсутствуют сведения о стоимости земель, приведенных в культурное состояние. Капиталы госхозяйства явно преуменьшены. По транспорту отсутствуют сведения о стоимости портовых сооружений (Владивостокского и Николаевского), данные о предприятиях связи и шоссейно-грунтовых дорогах и стоимость морского и речного флота. Очевидно, указанные дефекты представится возможным пополнить при разработке контрольных цифр на 1927-1928 гг.

Несмотря на некоторую неполноту сведений (отсутствующие данные будут колебаться примерно от 1/6 до 1/8 всех основных капиталов), представляется возможным дать картину соотношений капиталов в основных отраслях хозяйства.

В состав учета вошли основные капиталы: в сельском хозяйстве, государственный, кооперативный и частный, в промышленности - цензовой, нецензовой, включая и кустарно-ремесленную, в транспорте - железнодорожном, торговле, жилищном хозяйстве и коммунальном хозяйстве. <..>

Основной капитал сосредоточен в сельском хозяйстве и транспорте. На долю остальных отраслей приходится 1/7 от общего количества.

Все виды основных капиталов имеют тенденцию к постепенному возрастанию, за исключением транспорта, вложения в который не покрывают его естественного износа. Переходим к детальному анализу основных капиталов.

Сельское хозяйство. В состав основного капитала в частном сельском хозяйстве входят: скот, птица, пчелы, постройки, инвентарь.

В государственном сельском хозяйстве основные капиталы завязаны в мелиоративных установках, в учреждениях ветеринарной и агрономической сети и организациях опытного характера.

В состав кооперативного сектора сельского хозяйства входят артели, колхозы и коммуны. Основной капитал исчислен по тем же подразделениям, как и в частном сельском хозяйстве. <...>

Таким образом, роль обобществленных секторов в сельском хозяйстве значительно возрастает особенно в 1926-1927 гг.

Еще в 1923 г., когда сельское хозяйство находилось в состоянии расстрой- 
ства, на долю его основных капиталов приходилось $32,5 \%$ от общего количества; к 1926-1927 гг. сельское хозяйство сохраняет свою долю в возрастающих основных капиталах края $(32,4 \%)$.

Сельское хозяйство принадлежит к тем отраслям, в которых основные фонды наиболее быстро разрушаются и так же быстро восстанавливаются. <...>

Восстановление стада и приобретение сельхозинвентаря играло главнейшую роль в капитальных затратах сельского хозяйства. Строение вложений в кооперативное сельское хозяйство аналогично частному сектору, они, главным образом, состоят из вложений по скоту.

Что касается динамики вложений в государственный сектор, то эти вложения определяются в большей мере ассигнованиями по сметам НК3. Вложения в 1926-1927 гг. в 6 млн руб. определяются расходами по колонизации и опытному делу.

Капиталы промышленности учтены наиболее полно; сюда вошли все предприятия цензовой промышленности - государственной, кооперативной и частной.

Кроме того, по материалам обследования 1925 г., учтена мелкая кустарно-ремесленная и нецензовая промышленность. В отношении накопления основных капиталов в промышленности мы имеем условия, совершенно противоположные сельскому хозяйству. Фонды промышленности наиболее долго сохраняются, но вместе с тем, разрушенные, наиболее трудно восстанавливаются. Если накопление основных фондов в сельском хозяйстве идет полностью за счет создания новых ценностей, то увеличение основных фондов в промышленности ДВК шло в основном за счет пуска в ход сохранившегося, но бездействующего оборудования без больших на то затрат, и лишь в редких случаях организации новых предприятий.

Фонды промышленности в основных капиталах края составляют незначительную долю, то есть $4,4 \%<\ldots>$.

Основные фонды промышленности имеют тенденцию к постепенному увеличению, особенно это наблюдается в отношении государственной промышленности, которая за 4 года увеличила свои основные капиталы на 10 млн руб.; что же касается частной промышленности, то ее положение остается стабилизированным. Это объясняется тем, что частная промышленность преимущественно является мелкой кустарно-ремесленной промышленностью с небольшими затратами на основной капитал, фонды которой претерпевают самые незначительные колебания, в зависимости от числа ремесленников, и не имеют тех резких движений, как это наблюдается в государственной промышленности. <..>

Роль мелкой кустарной промышленности в доле всей частной занимает все возрастающее место. 
На основной капитал транспорта из всех фондов ДВК приходится 47,4\%. Такая колоссальная стоимость основных фондов транспорта объясняется тем, что протяженность эксплуатационной сети ДВК в 1913 г. к общесоюзной составляла 3,9\%, в 1923-1924 гг. -6,2\%, в 1926-1927 гг. - 6,4\%. Резкое увеличение сети в 1923-1924 гг. объясняется пуском в эксплуатацию в 1914-1915 гг. Амурской дороги. Кроме, того, построечная стоимость дорог ДВК несколько повышена против общесоюзных, так как дороги строились в тяжелых условиях, с большой затратой материалов и человеческих сил.

К 1923-1924 гг. основные капиталы транспорта очищены за списанием с его баланса 138 млн руб. изношенного негодного имущества за период с 1913 г. по 1923-1924 гг.

В состав транспорта входят: постройки и сооружения, подвижной состав, колесный парк и инвентарное имущество. $<\ldots>$

Из всех основных фондов ДВК только железнодорожный транспорт в отношении накопления дает отрицательные показатели. Особенно это сказывается в отношении построек и искусственных сооружений, где износ до сих пор превышает вложения. По остальным элементам намечается стабилизация фондов. Восстановление транспорта в ближайшие годы потребует для приостановления его разрушения более мощных вложений, чем это было до сих пор. <...>

Жилищное хозяйство. В отношении пополнения своих фондов переживает бурный рост, доля вложений, начиная с 1923 г., все время увеличивается. Но все же растущие вложения не удовлетворяют действительным потребностям населения и отстают от возрастающих требований населения на жилплощадь. <...>

Вложения в строительство по преимушеству в равных долях распределяется между госорганизациями и частниками; роль кооперации незначительна и от общей суммы вложений составляет всего лишь 3-5\%. <...>

Производственные фонды, за исключением износа, дают более медленную динамику своего движения и за период четырехлетия увеличились всего только на 58 млн руб., то есть на 12\% от 1923-1924 гг. В общих фондах жилищное хозяйство составляет в 1923-1924 гг. 25,2\%, а к 1926-1927 гг. $-24 \%$. <..>

В отношении накопления основных фондов промышленность, сельское хозяйство и торговля сделали наибольшие успехи. Транспорт и жилхозяйство надо отнести к отстающим отраслям. Коммунальное хозяйство в большей мере пополнило свои фонды за счет муниципализации домовладений и бесхозяйственных имуществ.

Обращаясь к анализу соотношения секторов по увеличению капиталов в крае, мы должны из вложений исключить износ, представляющий собой в большинстве случаев нормальную амортизацию капитала. <...> 
Отсюда видно, что:

1) вложения (новые) в частное хозяйство значительно превышают вложения в хозяйство обобществленное;

2) частные вложения направляются преимущественно в крестьянское хозяйство; частные вложения в прочие отрасли хозяйства невелики и сосредотачиваются преимущественно в жилищном хозяйстве;

3) кооперативные вложения невелики и после 1924-1925 гг. падают; преимущественно они направляются в торговлю и кооперативное сельское хозяйство;

4) государственные вложения (новые) весьма невелики; капиталовложение в промышленность идет впереди других отраслей, но все же незначительно; вложение капиталов в сельское хозяйство до 1926-1927 гг. было ничтожно и только 1926-1927 гг., в связи с колонизацией, дали резкий рост; в транспорте до сих пор идет разрушение капитала. В результате таких процессов мы получаем серьезные смещения в роли секторов в капиталонакоплении, невыгодные для обобществленных секторов. <...>

Кооперативный сектор дает резкое возрастание капиталов, но при небольшой величине их они не имеют серьезного экономического значения. По государственному сектору только 1926-1927 гг. должны дать некоторое улучшение положения. Наоборот, частный сектор дает сильный рост капиталов в крестьянском хозяйстве. В значительной степени это объясняется тем, что крестьянское хозяйство в 1923-1924 гг. было на весьма низкой ступени капиталообеспечения, но тем не менее этого отрицательного вывода о некотором нежелательном изменении строения наших основных капиталов не опровергает.

1926-1927 гг. должны, как уже указывалось, внести некоторое изменение в это положение ввиду предполагающихся крупных затрат на государственное строительство, в частности, он должен усилить долю государства в затратах на сельское хозяйство (через колонизационные мероприятия) и обеспечить ему большее влияние на его развитие. <...>

Таким образом, главные средства предполагается бросить в крупную промышленность (лес, рыба, золото) и в сельское хозяйство, что соответствует основной спецификации края как сырьевого колонизуемого района.

\section{XII. ЖИЛСТРОИТЕЛЬСТВО ДВК}

Темп городского жилищного строительства в крае в довоенное время зависел от отдельных государственных мероприятий, за счет которых населением производились колоссальные денежные накопления. Использование местных ресурсов (золото) также оказало свое влияние, но все же ка- 
зенные деньги в деле строительства сыграли основную роль. Общий объем жилищного строительства в 1913 г. по четырем крупным городам достигал 10843,5 тыс. руб. <...>

К началу 1923-1924 гг. жилищное строительство только постепенно начинает развиваться. Его характер не носит темпа широкого хозяйственного восстановления. Большинство домов строится из старого материала или перевозится с одного места на другое с незначительными достройками и заменой старых частей построек новыми. Размеры домов колеблются в среднем от 100 до 500 м $^{3}$ в объеме. Постройки носят исключительный характер удовлетворения собственных нужд и, по сравнению с масштабом возведения строений в прошлом, являются карликовыми. В небольших городах определяется новый тип экономического жилстроительства, появляются небольшие строения с насыпными стенками из досок. Застраиваются преимущественно окраины городов, причем постройки в массе, за редкими исключениями, рассчитаны производством на один строительный сезон.

По наиболее крупным пяти городам края органами технического надзора учтено всего лишь 200 новых строений. Нежилые строения не играют большой роли (47). Достройка и восстановление наибольшие по г. Хабаровску, где в сезон 1923-1924 гг. шла усиленная подготовка жилищного фонда для учреждений и их сотрудников, ввиду перенесения краевого центра из Читы. Надо полагать, что темп строительства в указанных пяти городах был несколько шире фиксированных цифр. Большинство строений на окраинах не поддавалось точному учету, и постройки производились самовольно без каких бы то ни было на то разрешений.

Жилищное строительство в 1924-1925 гг. характеризуется несколько иными показателями. На рынках появляются строительные материалы, в особенности скобяной товар, который отсутствовал до сего времени. Темп строительства по сравнению с прошлым годом удваивается. Всего было произведено жилых 432 новых постройки и восстановлено 96 построек общим объемом 238,4 тыс. м².

Нежилых построено 114 зданий и восстановлено 26, общим объемом в 57,1 тыс. $\mathrm{M}^{3}$.

Вместе с деревянными постройками постепенно начинают появляться каменные строения. Чита, Николаевск-на-Амуре и Владивосток по темпу строительства опережают другие. Строительство в Чите характеризуется застройкой рабочих окраин. Хабаровск и Владивосток восстанавливают в значительных размерах свой разрушенный жилфонд благодаря росту населения этих городов и оживлению хозяйственной жизни края. В общем строительстве госорганы начинают играть большое значение, занимая по кубатуре до $40 \%$ всего строительства, что отличает их по размерам от строительства, про- 
изводимого частным капиталом. Роль кооперации по-прежнему остается незначительной: на ее долю в общем итоге падает всего до 3,7\%.

Характеристика 1925-1926 гг. по жилищному строительству является неполной, благодаря тому, что по техническим данным учета мы имеем сведения всего лишь только за I полугодие этого года, включая апрель месяц. Темп же наиболее интенсивного строительства, несомненно, будет развит в период май по сентябрь включительно.

За I полугодие 1925-1926 гг. жилых построек предполагается построить 367, восстановить 59 общим объемом 114,2 тыс. м³ , нежилых новых построить 50, восстановить 12, общим объемом 47 тыс. м $^{3}$.

Успехи строительства будут зависеть в большой мере от рынка труда и наличия строительных материалов. Современное положение характеризуется отсутствием квалифицированных рабочих строителей и резким повышением цен на строительный материал - кирпич, бутовый камень и известь.

Распределяя строительство по количеству построек между госорганами, кооперацией и частниками, получаем следующие соотношения: на долю госорганов падает 6,2\%, кооперацию - 2,1\%, частников - 92,7\%. Совершенно новые соотношения выявятся, если строительство разбить по объему производящихся построек. Несмотря на незначительное количество построек, производимых за счет госкапитала, в общей доле строительства они занимают 11,3\%, что указывает на масштаб производимых работ. Доля кооперации не возрастает и остается на прежнем уровне в 3,8\%. Частный капитал, занимая 91,7\% по количеству производимых построек, по кубатуре этих построек занимает всего лишь 51,9\%.

Пользуясь расценками Дальстроя, исчисленными по всему краю в отношении стоимости производства $1 \mathrm{~m}^{3}$ работ на жилые и нежилые постройки с подразделением их по материалу (капитальный ремонт выделен отдельно), в ценностном выражении стоимость произведенных построек по крупным городам определится в следующем виде: 1923-1924 гг. - 1894,6 тыс. руб., 1924-1925 гг. - 4262,2 тыс. руб., 1925-1926 гг. - 7312,7 тыс. руб.

Сопоставляя с цифрой довоенного строительства наши показатели (учитывая не только объем вновь построенных жилищ, но и объем капитального ремонта жилых построек), мы будем иметь следующие соотношения: в 19231924 гг. - 12\%, в 1924-1925 гг. - 28\% и в 1925-1926 гг. - 39\%. Учитывая, что объем строительства в городах второстепенного типа значительно меньше и стоимость построек за единицу ниже, поправку на строительство в них можно определить в $20 \%$. <...>

Насколько жилищное строительство советского трехлетия удовлетворяет действительные потребности населения, можно судить из сравнения трех основных элементов: прирост городского населения, рост строительства в городах и потребность в жилой площади. <...> 
Учитывая только один естественный прирост городского населения края $(2,2 \%)$, без механического увеличения населения городов, современное жилищное строительство покрывает в 1923-1924 гг. 25\% потребности и в последующие годы 55,5\% и 66\%. Современное состояние полезного жилого фонда резко ухудшилось.

По данным переписи 1923 г., весь жилфонд заключался в 2635500 м² (7 $906500 \mathrm{~m}^{3}$ ) и жилищная норма на человека определялась в 5,55 м² $\left(19,65\right.$ м$\left.^{3}\right)$, то есть была много ниже санитарной; общий недостаток жилой площади к 1913 г. определялся в 535000 м² (1 605000 м $\left.^{3}\right)^{1}$. При этом к 1926 г. он возрос до 660000 м², или 1981553 м³. Для покрытия этого недостатка в жилой площади, рассчитывая, что строения будут смешанного характера, то есть каменные и деревянные, пришлось бы единовременно вложить до 40 млн руб. ${ }^{2}$ Такие средства государством для разрешения жилищного кризиса, конечно, единовременно брошены быть не могут, и, следовательно, недостаток в жилфонде надо считать длительным явлением. Пополнение жилфонда приходится рассматривать лишь в плоскости соответствия естественному росту населения.

Контрольную цифру по жилстроительству на 1926-1927 гг. на основании темпа его роста за прошлые годы представляется возможным определить в 9000000 руб., то есть на 25\% выше предыдущего года. Такой уровень строительства может быть достигнут при условии, что госорганы сохранят темп строительства прошлого года, то есть по отношению к частному составят до $50 \%$. Частное строительство имеет тенденцию к неуклонному росту и, очевидно, в будущем году перейдет от удовлетворения нужд потребительского характера к расширенному воспроизводству жилищного фонда.

Пытаясь подвести итоги по контрольным цифрам ДВК на 1926-1927 гг., мы можем констатировать, что:

1. Хозяйство ДВК в 1926-1927 гг. продолжит рост своей продукции, темп которого можно считать колеблющимся около 15\%. Наибольший прирост должно дать лесное хозяйство, соответствующее спецификации Дальневосточного края; за ним идут промышленность $(13,8 \%)$ и сельское хозяйство земледелие $(13,7 \%)$ и животноводство $(10,1 \%)$; рыбное хозяйство будет переживать период временной (годовой) депрессии по стихийным причинам; депрессия пушного хозяйства является более длительной.

2. Условно чистая продукция растет несколько быстрее $(16,7 \%)$, чем валовая $(13,4 \%)$ за счет большего роста добывающей промышленности.

\footnotetext{
${ }^{1}$ При исчислениях не принята в расчет степень естественного износа строений, который надо считать в среднем в 1,4\% от суммы основного капитала к началу каждого года, что за три года составит $131000 \mathrm{M}^{2}$.

2 При условии лишь восстановления имеющихся, но частично разрушенных зданий эту цифру можно снизить до 15 млн руб.
} 
3. Если лесное хозяйство отнести к промышленности, то предстоящий год должен продолжить сдвиг в сторону индустриализации края (по производству), который должен несколько выровнять положение, наметившееся в 1923-1924 гг, в пользу сильной аграризации края.

4. Прирост валовой продукции обгоняет прирост числа занятых лиц (на $10,5 \%$ ) и прирост капиталов (на 6\%), что показывает, что коэффициент их использования растет; в некоторых отраслях (золотая, каменноугольная, рыбная, мукомольная и пр.) он доведен до предела и дальнейшее развитие этих отраслей упирается в необходимость капитального строительства; в других (лесная, та же каменноугольная) в минимуме находится труд, в особенности квалифицированный.

5. В приросте народнохозяйственной продукции края первое место принадлежит госсектору $(24,7 \%)$; за ним идет кооперативный $(13,1 \%)$ и частный $(10,7 \%)$. Вообще же в строении валовой продукции частный сектор за счет крестьянства и японского рыболовства (12,4\% всей продукции края) имеет подавляющее положение; это обязывает уделить особое внимание укреплению госсектора в производстве края.

6. Товарооборот края растет несколько быстрее производства (18\%) за счет большого роста товарной массы, увеличения рыночности хозяйства в связи с его специализацией и отхода от полунатуральных форм, укоренившихся за время хозяйственной разрухи.

7. Недостаток оборотных средств в государственном и кооперативном секторе, направляемых в большей доле в производство, увеличивает в товарообороте роль частника (прирост 17,8\% против $13 \%$ госсектора), это необходимо учесть и выправить положение за счет большего усиления кооперативного сектора.

8. В строении товарной массы происходят крупные улучшения за счет резкого увеличения доли ее внутреннего происхождения $(15,7 \%$ прироста по сельскохозяйственной и 19,8\% по промышленной); довольно крупное возрастание импорта объясняется потребностями капитального строительства, с одной стороны, и резким сокращением этого источника пополнения товарных фондов края против довоенного времени (16,7\% от 1913 г.); кроме того, в составе и всей товарной массы, и особенно ввозной происходит сдвиг в пользу промтоваров.

9. В отношении внешнего товарооборота края на предстоящий год намечается сокращение отрицательного сальдо; с одной стороны, это служит показателем усиления края, но в то же время, учитывая колонизационное его значение, вряд ли это можно считать для него благоприятным, особенно если иметь в виду чрезвычайно резкое сокращение этого отрицательного сальдо по сравнению с довоенным временем. 
10. В отношении цен на 1926-1927 гг. намечается ряд крупных задач в виде перестройки цен при общей их стабилизации в направлении повышения индексов отставших групп за счет снижения прочих; намечается также сближение цен производителя и оптовых за счет рационализации аппарата.

11. Бюджет к расходной части в предстоящем году дает резкое снижение темпа роста (с 40,3\% в 1925-1926 гг. до 24,7\%), причем большая доля этого роста приходится на транспорт и связь; наоборот, доходная часть дает увеличение темпа роста с 8,6\% в 1925-1926 гг. до 19,8 \% в 1926-1927 гг. Это также подчеркивает, с одной стороны, хозяйственное усиление края, а с другой, сокращение притока средств в него извне.

12. Чтобы обеспечить намеченный рост производства и товарооборота, пришлось проектировать в несколько повышенном (но все же меньшем, чем в 1925-1926 г.) темпе рост кредита, кроме того, это вызывалось необходимостью кредитования переселенцев, приезжающих в край из Европейской России большей частью без необходимого денежного обеспечения.

13. В отношении наемного труда можно рассчитывать на некоторое повышение производительности труда.

Роль государственного сектора в отношении охвата наемного труда все увеличивается за счет количественного возрастания наемного труда, приходящегося на его долю, и повышенной квалификации этого труда.

14. В отношении капиталонакопления край отстает от роста производства, что поставит его в ближайшем будущем перед серьезными производственными затруднениями. Кроме того, приходится особо учитывать, что капиталонакопление в частном секторе идет несколько быстрее, чем в государственном; развертывание концессий в ближайшем будущем может еще больше усилить это расхождение. Поэтому на увеличение капитальных вложений по государственному и кооперативному секторам нужно обратить особое внимание и безусловно выполнить программу капиталовложений, намеченных на 1926-1927 гг.

\section{KEY ECONOMIC FIGURES OF THE FAR EASTERN REGION FOR 1926-1927}

Planned targets of the Far East's national economy are given, which were projected by the Far Eastern regional Planning Committee for 1926-1927. An analysis is made of all the elements by the main social sectors: public sector, cooperative and private sectors, in order to determine their dynamics and relationships in the region's national economy. Linking the separate parts of the system together was done partly by the balance method, partly by the method of verifying coefficients.

Keywords: national economy, targets, directives, Far Eastern Planning Committee, Far East. 